\title{
¿Cómo se hace frente al desclasamiento social educativo en España? Tipología de los perfiles sociales y lógicas estratégicas de los titulados treintañeros en tiempos de crisis
}

\author{
Victoria Bogino-Larrambebere \\ Universidad Pública de Navarra \\ victoria.bogino@unavarra.es
}

Recepción: 17-11-2017

Aceptación: 19-01-2019

Publicación: 26-07-2019

\section{Resumen}

El presente artículo se propone identificar una tipología de los perfiles sociales afectados por el desclasamiento social educativo y desentrañar sus lógicas estratégicas ante tal fenómeno, en el seno de la cohorte de treintañeros con título superior y en el contexto de crisis económica en España. Para ello se ha optado por una complementariedad entre una aproximación cuantitativa y una aproximación cualitativa. Este diseño mixto es secuencial y está compuesto por dos fases. La primera consiste en realizar un análisis de correspondencias múltiples (ACM) y un análisis de clasificación automática (ACL) de partición jerárquica, a partir de los datos de la Encuesta de Condiciones de Vida (ECV) de 2011. La segunda fase reside en realizar entrevistas en profundidad a los titulados afectados por el desclasamiento. Los resultados muestran tres tipos de perfiles sociales, que se distinguen prioritariamente por el nivel de educación de sus padres y despliegan diferentes lógicas estratégicas ante el desclasamiento social educativo: a) reconvertirse para cambiar de campo profesional y con la idea de reenclasarse socialmente; $b$ ) resituarse a través del desplazamiento geográfico o de régimen de empleo y con la intención de responder a sus ambiciones profesionales, y $c$ ) resistir en sus empleos y/o intentar de acceder a un empleo público, para evitar la pauperización y asegurarse una cierta estabilidad económica.

Palabras clave: educación superior; inconsistencia de estatus; cohorte de treintañeros; estrategias; métodos mixtos 
Abstract. Dealing with socio-educational downclassing in Spain: A typology of social profiles and strategies among thirty-year-old graduates in times of crisis

This article aims to identify a typology of social profiles affected by socio-educational downclassing in Spain and unravel the strategies employed in a cohort of thirty to thirtynine-year-olds faced with this phenomenon in a context of economic crisis. For this purpose, a sequential, mixed quantitative and qualitative approach consisting of two phases has been used. In the first phase, multiple correspondence analysis (MCA) and automatic classification analysis (ACA) based on hierarchical partitioning are performed using data from the Spanish Living Conditions Survey (ECV) of 2011. In the second phase, in-depth interviews are carried out with individuals from each of the social profiles. The results reveal three types of social profiles, which are distinguished primarily by the educational levels of their parents and which deploy different strategies to deal with socio-educational downclassing: (1) "reconversion" to change the professional field with the idea of upclassing; (2) "relocation" through geographical or employment displacement with the intention of fulfilling their professional ambitions; and (3) "resistance" in their jobs and/or attempting to gain access to public employment to avoid impoverishment and ensure economic stability.

Keywords: higher education; status inconsistency; thirty-year-old cohort; strategies; mixed methods

\author{
Sumario \\ 1. Introducción 4. Conclusiones \\ 2. Estrategia metodológica Referencias bibliográficas \\ 3. Resultados Anexos
}

\title{
1. Introducción
}

En la literatura sociológica el desclasamiento se concibe como el producto de una desviación con respecto a la pendiente de una trayectoria colectiva (Bourdieu, 1988) y se pueden distinguir tres grandes formas de observar el fenómeno:

1. El desclasamiento social intergeneracional (cuando los hijos y las hijas se encuentran en una posición social inferior a la de sus padres) (Thijssen y Wolbers, 2016; Li y Devine, 2011; Peugny, 2009; Goldthorpe y Jackson, 2007; Chauvel, 1998).

2. El desclasamiento social intrageneracional (cuando se produce una ruptura en la trayectoria profesional de los individuos y una pérdida de su posición social) (Alm, 2011; Wilson, 2009; Maurin, 2009; Newman, 1988).

3. El desclasamiento escolar (cuando se aprecia una disminución del rendimiento social de los títulos en comparación con generaciones anteriores y sobreeducación) (Chauvel, 2006; Duru-Bellat, 2006; Giret et al., 2006; Baudelot y Establet, 2000). 
Esta investigación se propone abordar la cuestión del desclasamiento desde otra perspectiva, que hace hincapié en la inconsistencia de estatus social educativo y se denomina desclasamiento social educativo. Esta perspectiva se puede conjugar y se diferencia de las anteriores. Su objeto de estudio son los individuos de 30 a 39 años que se sitúan en una posición alta de la estructura educativa (título superior, ISCED-97 nivel 5 y 6 ) y en una posición relativamente más baja de la estructura ocupacional y salarial, a saber: empleados, obreros (ISCO-08 de la categoría 4 a la 9) y desempleados, con un salario igual o inferior a la mediana de la distribución salarial del conjunto de los individuos treintañeros con título superior ${ }^{1}$.

El objetivo de este artículo es identificar una tipología de los perfiles sociales afectados por el desclasamiento social educativo en el seno de la cohorte de treintañeros en España, para luego desentrañar sus lógicas estratégicas ante tal fenómeno. La pregunta que se intenta responder es la siguiente: ¿cómo se hace frente al desclasamiento social educativo? Este cuestionamiento apunta a captar el «sentido objetivo» del desclasamiento social educativo, para luego dar cuenta de su «sentido vivido» (Bourdieu, 1988).

En este marco, para abordar el modo en que los individuos afrontan el desclasamiento, un concepto central es el de estrategias de reproducción social. Estas estrategias son entendidas como prácticas, por medio de las cuales los individuos tienden, de manera consciente o inconsciente, a mantener o mejorar su posición en la estructura de las relaciones de clase (Bourdieu, 1988: 122). En otras palabras, se parte del supuesto de que los titulados en situación de desclasamiento social educativo despliegan una serie de lógicas estratégicas para evitar la pauperización o buscar el reenclasamiento en términos de estatus educativo-social, e incluso para incorporarse a su trayectoria de clase en el caso de los titulados "herederos» o prolongar el curso interrumpido de una trayectoria que se daba por descontada (o inaccesible) en el caso de los titulados «advenedizos» (Bourdieu, 1988).

Las estrategias de reproducción dependen de un conjunto de factores ${ }^{2}$ :

1. Del volumen y la estructura del capital a reproducir (esto es, los diferentes recursos con los que cuentan los agentes: capital económico, capital cultural, capital social, capital simbólico) y de su trayectoria histórica.

2. Del estado de los instrumentos de reproducción disponibles, es decir, de las distintas opciones objetivas que los agentes tienen para implementar estrategias (como, por ejemplo, el estado del mercado de trabajo, de la intervención estatal).

1. A partir de los datos de la ECV de 2011 se ha calculado la mediana de la distribución salarial del conjunto de titulados superiores de 30 a 39 años y se ha constatado que esta se sitúa en 1.200 euros netos mensuales.

2. En los trabajos de Gutiérrez $(2004,2005)$ se puede observar tal esquematización sobre los factores que influyen en las estrategias de reproducción y una explicación más detallada de todos sus aspectos. 
3. Del estado de la relación de fuerzas entre las clases, a saber, del rendimiento diferencial que los distintos instrumentos de reproducción pueden ofrecer a las inversiones de cada clase o fracción de clase.

4. De los habitus incorporados por los agentes sociales, que definen los esquemas de percepción, de apreciación y de acción, ligados a la definición práctica de lo posible y lo imposible, de lo pensable y lo impensable.

Siguiendo la propuesta teórica de Bourdieu (1988), existe una relación dinámica entre, por un lado, las estructuras sociales externas y las posiciones ocupadas por los sujetos en estas estructuras y, por otro, las estructuras sociales internalizadas, incorporadas al agente en forma de esquemas de percepción, pensamiento y acción. Estas últimas estructuras son, precisamente, los habitus. Los habitus expresan las disposiciones incorporadas por los agentes a lo largo de su trayectoria individual y en relación con la trayectoria modal de la clase. Estos constituyen a la vez un recurso y una limitación, porque están ligados a las condiciones sociales de su producción y a los condicionamientos que ellas implican. Es importante recordar que los habitus "confieren una significación diferente a posiciones homólogas y un margen de maniobra diferente a dos agentes que ocupan la misma posición en un campo determinado. Es en este sentido que la noción es importante para caracterizar la diversidad de los espacios estratégicos» (Gutiérrez, 2004: 54). Pero, igualmente, es posible reconocer semejanzas entre los sistemas de disposiciones de los individuos que comparten similares condiciones objetivas de vida. De este modo, el habitus de clase supone que todos los miembros de una misma clase tienen mayores probabilidades de verse enfrentados a las mismas situaciones y a los mismos condicionamientos entre sí que en relación con los miembros de otra clase. En suma, esta herramienta conceptual permite entender a los titulados desclasados como «agentes», aunque sus acciones no necesariamente sean entendidas como una verdadera intención estratégica de forma consciente. Se trata más bien de comprender la «razonabilidad» de sus prácticas.

Este artículo se divide en tres secciones. La primera expone la estrategia metodológica a partir de métodos mixtos. La segunda sección muestra los resultados sobre tipología de los perfiles sociales y sus lógicas estratégicas ante el desclasamiento. En la tercera y última sección se presentan las conclusiones, en las que se realiza una recapitulación de los principales hallazgos.

\section{Estrategia metodológica}

Esta investigación ha optado por una complementariedad entre una aproximación cuantitativa y una aproximación cualitativa. Se trata de una propuesta mixta, dado que se utilizan distintas técnicas de análisis cuyas cualidades son complementarias. El diseño es secuencial y está compuesto por dos fases. Su particularidad es que los datos analizados en la primera fase sirven para mejorar la obtención y el análisis de los datos de la segunda fase (Verd y López-Roldán, 2008). 


\subsection{La fase de aproximación cuantitativa}

La primera fase consiste en la explotación de los datos de la Encuesta de Condiciones de Vida (ECV) de 2011, que se lleva a cabo por el Instituto Nacional de Estadística (INE) de España y está armonizada con el panel European Statistics on Income and Linving Conditions (EU-SILC) de Eurostat. La especificidad de la ECV de 2011 es que incorpora el módulo «Trasmisión intergeneracional de la pobreza», en el que se recogen variables referentes al origen social de los individuos interrogados.

Para identificar una tipología de los perfiles sociales de los titulados treintañeros afectados por el desclasamiento $(N=491)$, las técnicas que se han utilizado son el análisis de correspondencias múltiples (ACM) y el análisis de clasificación automática (ACL) de partición jerárquica ${ }^{3}$. La aplicación integrada de estas dos técnicas se ha llevado a cabo con el programa estadístico SPAD y tiene la ventaja de garantizar una primera estructuración del fenómeno estudiado (dimensionalización), para luego proceder al proceso de clasificación a partir del cual se desprenden los tipos y la tipología. Desde el punto metodológico, el procedimiento de obtención de la tipología consiste en tres fases analíticas fundamentales (Domínguez y López-Roldán, 1996):

1. Después de la selección de las variables y de un análisis descriptivo previo para tratarlas, a partir de un ACM se realiza un análisis de dimensionalización para estructurar inicialmente las variables originales y derivar de ello los principales factores de diferenciación de los individuos.

2. En función de los resultados del análisis precedente y sobre la base de las variables factoriales, se procede a realizar un análisis de clasificación de las unidades con un ACL, que deriva en un conjunto de tipos significativos que estructuran el fenómeno estudiado.

3. Vinculada a ambos procesos, la obtención y la identificación de la tipología, así como la descripción de los perfiles que la caracterizan y la validación de estos resultados.

En este análisis se han seleccionado siete variables activas con 26 categorías (que construyen los ejes significativos y que clasifican a los individuos) y dos variables ilustrativas con 5 categorías (que afectan a la información, pero no generan los ejes ni clasifican a los individuos) (tabla 1). Se ha optado por este número de variables para facilitar la captación de los entrevistados en el trabajo de campo cualitativo, ya que se pretende que los entrevistados se adecuen lo mejor posible a cada uno de los perfiles.

3. En este artículo se ha optado por estas técnicas debido a que son las más idóneas para responder a nuestro propósito de identificar una tipología de los perfiles sociales de los titulados en situación de desclasamiento (Domínguez y López-Roldán, 1996). En un estudio previo se ha realizado un análisis de regresión para detectar los determinantes del desclasamiento social educativo. Para encontrar tales resultados, véase Bogino-Larrambebere (2016). 
Tabla 1. Descripción de las variables activas e ilustrativas del análisis de correspondencias múltiples

\begin{tabular}{|c|c|}
\hline Variables activas & $\%$ \\
\hline \multicolumn{2}{|l|}{ Sexo } \\
\hline Mujer & 67 \\
\hline Hombre & 33 \\
\hline \multicolumn{2}{|l|}{ Grupo de edad } \\
\hline 30-34 años & 52 \\
\hline 35-39 años & 48 \\
\hline \multicolumn{2}{|l|}{ Nivel de educación superior del individuo } \\
\hline FP superior & 41 \\
\hline Diplomatura & 28 \\
\hline Licenciatura & 27 \\
\hline Esp/Postrgrado & 4 \\
\hline \multicolumn{2}{|l|}{ Nivel de educación de la madre } \\
\hline Nivel bajo & 82 \\
\hline Nivel medio & 10 \\
\hline Nivel alto & 8 \\
\hline \multicolumn{2}{|l|}{ Nivel de educación del padre } \\
\hline Nivel bajo & 78 \\
\hline Nivel medio & 10 \\
\hline Nivel alto & 12 \\
\hline \multicolumn{2}{|l|}{ Situación ocupacional de la madre } \\
\hline Directoras y gerentes & 2 \\
\hline Profesionales científicas & 5 \\
\hline Técnicas y profesionales nivel medio & 2 \\
\hline Empleadas & 13 \\
\hline Obreras & 11 \\
\hline Paradas o inactivas & 67 \\
\hline \multicolumn{2}{|l|}{ Situación ocupacional del padre } \\
\hline Directores y gerentes & 8 \\
\hline Profesionales científicos & 5 \\
\hline Técnicos y profesionales nivel medio & 11 \\
\hline Empleados & 17 \\
\hline Obreros & 51 \\
\hline Parados o inactivos & 9 \\
\hline \multicolumn{2}{|l|}{ Variables ilustrativas } \\
\hline \multicolumn{2}{|l|}{ Cónyuge o pareja de hecho } \\
\hline Sí & 53 \\
\hline No & 47 \\
\hline \multicolumn{2}{|l|}{ Número de años en trabajos remunerados } \\
\hline Menos de 5 años & 13 \\
\hline De 5 a 10 años & 48 \\
\hline Más de 10 años & 39 \\
\hline
\end{tabular}

Fuente: elaboración propia a partir de los datos de la ECV de 2011. 


\subsection{La fase de aproximación cualitativa}

La segunda fase reside en la realización de entrevistas en profundidad a titulados treintañeros en situación de desclasamiento, que responden a cada uno de los perfiles sociales identificados en la parte cuantitativa. El trabajo de campo se ha llevado a cabo en Barcelona, entre los años 2012 y 2014 . La captación de los entrevistados se ha realizado a través de la estrategia «bola de nieve» $\mathrm{y}$, en total, se han realizado 26 entrevistas (véase en anexos la plantilla de los perfiles entrevistados y sus características). Esta captación se interrumpió cuando se alcanzó una relativa saturación de los discursos; esto es, cuando entrevistar a más personas no añadía ni enriquecía sustantivamente las narrativas ya obtenidas con la muestra existente (Bertaux, 2005; Callejo, 1998). Las entrevistas han sido grabadas, transcritas y analizadas con el programa Maxqda. El análisis de datos ha consistido en la organización conceptual de la información producida sobre la base de categorías significativas, priorizando el contenido de estas categorías y su interpretación, en detrimento de las frecuencias de los códigos.

El proceso de análisis concretamente ha consistido en tres fases. En un primer momento, se ha realizado una lectura diacrónica de las trayectorias y se ha hecho un paralelismo entre "tiempo biográfico y tiempo histórico y social» (Bertaux, 2005). A su vez, se han puesto en relación «las posiciones objetivas, las prácticas y los puntos de vistas subjetivos» de los entrevistados (Beaud y Weber, 2008: 266). En un segundo momento, se ha llevado a cabo una lectura temática y sincrónica de los relatos. Por último, se han establecido las similitudes y las diferencias entre los relatos de cada perfil social y luego entre los relatos de los diferentes perfiles sociales.

\section{Resultados}

\subsection{Tipología de los perfiles sociales}

A través de un uso conjunto del ACM y del ACL (López-Roldán, 1996; Domínguez y López Roldán, 1996), se han identificado los perfiles sociales más consistentes y diferenciados de los titulados treintañeros afectados por el desclasamiento.

Con el ACM se han obtenido dos factores principales de diferenciación. Por un lado, con el $82 \%$ de la varianza total, se configura el principal factor (horizontal) de diferenciación del conjunto de los titulados treintañeros en situación de desclasamiento. Este primer factor opone a los individuos que provienen de una familia de clase media-alta frente a los individuos que provienen de una familia de clase media-baja o trabajadora. Esto se debe a que las variables de descripción del nivel educativo y la situación ocupacional del padre y de la madre forman un grupo estrechamente ligado. Por otro lado, el segundo factor (vertical), de menor importancia que el primero, ya que concentra solamente el 13\% de la varianza, permite afinar y complementar la interpretación global del análisis de correspondencias múltiples. La variable que interviene principalmente en la contribución de este eje es el nivel educativo de 
Tabla 2. Caracterización de los factores por las variables activas

\begin{tabular}{lcc}
\hline Variables activas & Factor $\mathbf{1}$ & Factor $\mathbf{2}$ \\
\hline Sexo & 0,73 & 0,61 \\
Grupo de edad & 1,27 & 1,42 \\
Nivel de educación superior del individuo & 5,61 & 13,00 \\
Nivel de educación de la madre & 25,80 & 31,32 \\
Nivel de educación del padre & 23,13 & 20,85 \\
Situación ocupacional de la madre & 21,11 & 18,17 \\
Situación ocupacional del padre & 22,34 & 14,63 \\
\hline
\end{tabular}

Fuente: elaboración propia a partir de los datos de la ECV, 2011.

la madre, seguida del nivel educativo del padre. Aquí se opone a los individuos que provienen de estratos medios o elevados de la estratificación social, básicamente con relación al papel del capital cultural institucionalizado de la familia de origen. Resulta significativo, no obstante, que el sexo y el grupo de edad no se presentan como variables relevantes ni clasificatorias. A su vez, el nivel de educación superior de los individuos si bien es significativamente discriminatorio, define en menor medida a los diferentes tipos de perfiles (tabla 2).

Con el ACL se han establecido tres tipos de perfiles sociales. El primer tipo está formado por el 75\% de los casos, el segundo tipo agrupa el 15\% de los casos y el tercer tipo representa el $10 \%$ de los casos. Estos perfiles se muestran en la figura 1 y son los que se carcaterizan a continuación.

El tipo 1 (el 75\%) recoge a los individuos que provienen de una familia de clase media-baja y de clase trabajadora, en el que el padre y la madre destacan con un nivel de educación bajo. Para el caso de las madres, el 93\% tiene educación secundaria de primera etapa o inferior y el $74 \%$ de ellas están "paradas o inactivas (dedicadas a las tareas del hogar y del cuidado)» u ocupan la categoría ocupacional de "obreras» (ISCO-08 de la categoría de 6 a 9). Para el caso de los padres, un 89\% tiene educación secundaria de primera etapa o inferior y un 62\% son "obreros» (ISCO-08 de la categoría de 6 a 9). Además, con respecto al nivel de educación superior de los individuos, en este grupo predomina el nivel de «FP superior» (el 50\%) y, en menor medida, el de "diplomatura o equivalente» (el 25\%), así como el de «licenciatura o equivalente» (el 25\%). También es el grupo que presenta más tiempo de experiencia laboral, en tanto que el $42 \%$ hace más de diez años que se encuentra en trabajos remunerados (porporción levemente más elevada al $37 \%$ de la muestra total).

El tipo 2 (el 15\%) está formado principalmente por hijos e hijas de madres y de padres con un nivel de educación medio. Para el caso de las madres, el 46\% tiene educación secundaria de segunda etapa y el 36\% de ellas presenta una categoría ocupacional de «empleadas» (ISCO-08 de la categoría 4 a la 5). Para el caso de los padres, un $47 \%$ tiene educación secundaria de segunda etapa. Tal y como sucede en el caso de las madres con el mismo nivel de educación, este porcentaje se diferencia significativamente del conjunto de la muestra (el 9\%) 
Figura 1. Tipología de los perfiles sociales de los titulados afectados por el desclasamiento Factor 2

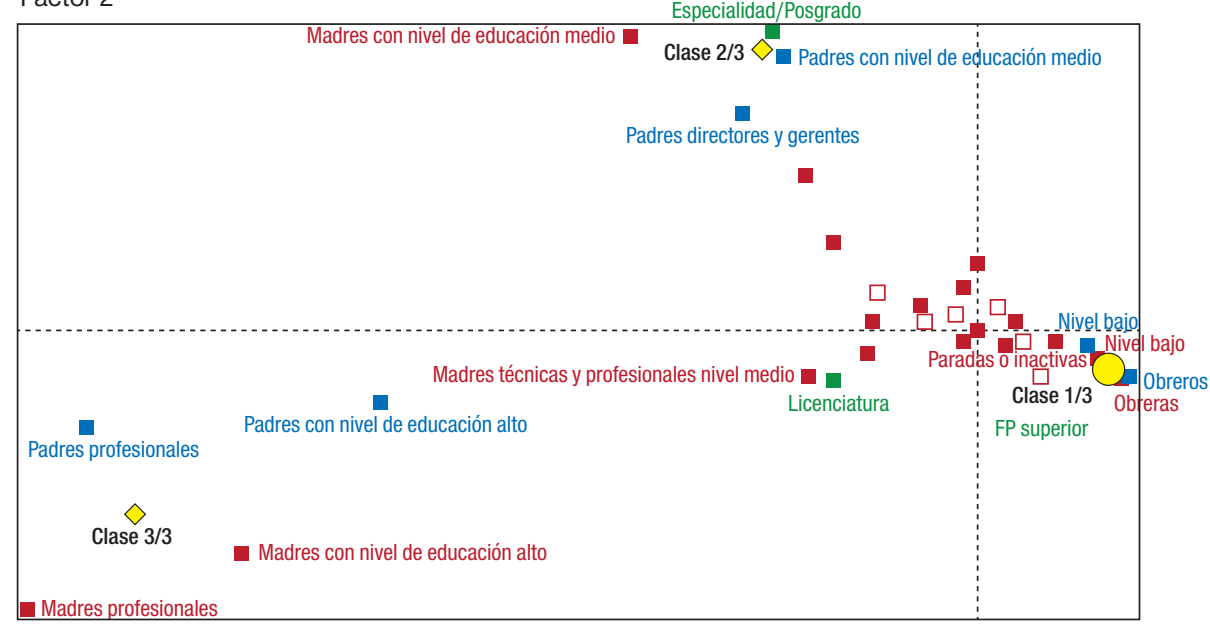

Factor 1

Fuente: elaboración propia a partir de los datos de la ECV, 2011.

y representa el $76 \%$ de todos los padres con educación secundaria de segunda etapa de la muestra. Los padres que conforman este grupo constituyen el 27\% de la categoría ocupacional de «empleados» (ISCO-08 de la categoría 4 a la 5) (porcentaje sobrerepresentado al $17 \%$ de la muestra global). No obstante, la categoría ocupacional más frecuente entre los padres de este grupo es la de «directivos y gerentes» (categoría 1 del ISCO-08) (el 32\%), donde están considerablemente sobrerrepresentados en comparación con el $8 \%$ de la muestra global. Sobre este punto, es posible realizar al menos dos tipos de interpretaciones. Por un lado, quizás estos padres han comenzado su carrera profesional en posiciones menos prestigiosas y han logrado ascender (promoción laboral) hasta alcazar la categoría más elevada de la estructura ocupacional; o bien, por otro lado, puede que estos básicamente se encuentren en la dirección de una pequeña empresa, puesto que el entramado empresarial de España está conformado fundamentalmente por este tipo de empresa. Si bien no se ha procedido a comprobar, se estima que esta segunda interpretación seguramente es la más adecuada.

En relación con el nivel de educación superior de los individuos, en este grupo se concentran aquellos treintañeros que realizaron "estudios de especialización o de postgrado» (el $22 \%$ con respecto al $4 \%$ de la muestra global, y el $80 \%$ de todos los individuos con estudios de especialización o de postgrado de la muestra). Aunque también son numerosos aquellos que poseen un nivel de «diplomatura o equivalente» (el $42 \%$ en el tipo y el $28 \%$ en la muestra total). Sumado a esto, en cuanto a la experiencia laboral, los individuos que se agrupan bajo este perfil se encuentran en una posición intermedia en compa- 
ración con los otros dos tipos: el número de años en trabajos remunerados que prevalece en este perfil oscila entre los seis y los diez años (el 58\%).

El tipo 3 (el 10\%) configura un perfil de individuos que provienen de una familia de clase media-alta, rica ante todo en capital cultural, en el que la madre y el padre destacan por un nivel de educación alto. Para el caso de las madres, el $71 \%$ tiene educación superior, porcentaje sustancialmente más elevado que el conjunto de la muestra (el 8\%), y representa el 74\% de todas las madres con educación superior de la muestra. En este grupo, el 51\% de las madres ocupa una categoría laboral de "profesionales científicas e intelectuales» (categoría 2 del ISCO-08) (por lo que están sobrerrepresentadas en comparación con el $4 \%$ de la muestra global). Para el caso de los padres, un 73\% tiene educación superior (el $12 \%$ en el total de la muestra) y un $46 \%$ son "profesionales científicos e intelectuales» (categoría 2 del ISCO-08) (por lo que, al igual que las madres en esta categoría laboral, están sobrerrepresentados en comparación con el $4 \%$ de la muestra general).

En cuanto a los datos relativos a los propios individuos, el nivel de educación superior que prevalece en este tipo es el de «licenciatura o equivalente» (el 49\%), de modo que este nivel se encuentra sobrerrepresentado a diferencia del $27 \%$ general. Además, este perfil es el que presenta menos años de experiencia laboral, puesto que la mayoría de los individuos no ha superado los cinco años en trabajos remunerados (el 24\%) (el 15\% en el total de la muestra).

\subsection{Lógicas estratégicas ante el desclasamiento}

A partir del análisis de comparación de las entrevistas, se han ido descubriendo ciertos rasgos específicos y desprendiendo tres modos de experiencias de hacer frente al desclasamiento social: reconvertirse, resituarse y resistir.

\subsubsection{Reconvertirse}

Esta experiencia se inscribe fundamentalmente en el perfil social menos afectado por el desclasamiento, el cual concentra a los titulados que provienen de una familia de clase media-alta con elevado capital cultural, en la que el padre y/o la madre poseen un nivel de educación superior y son profesionales. Para hacer frente al desclasamiento social educativo, la lógica estratégica que se presenta prioritaria en el haz de posibles de este tipo de perfil es la reconversión, ya sea a través de la formación y/o del autoempleo. Esta apunta hacia un desplazamiento de campo profesional, con el propósito de lograr el reenclasamiento social.

\section{La formación para la empleabilidad}

«Reconvertirme», «reinventarme», «reciclarme», «redirigirme» y «reorientarme» son las expresiones más frecuentemente utilizadas por quienes deciden realizar una nueva formación (un grado o un postgrado), básicamente para llevar a cabo una actividad profesional que difiere de aquella que tenían anteriormente y bajo la óptica de «hacerse empleables» (Serrano y Crespo, 2002). 
Teniendo en cuenta que en el transcurso de la crisis económica se ha producido un encarecimiento considerable del precio de las matrículas universitarias (Elias y Daza, 2014), muchos de los entrevistados han recurrido a la ayuda familiar para retomar su formación:

LLuc: Les pedí [a sus padres] un préstamo para hacer el máster [...]. A mí es algo que no me gusta, que me den pasta [...]. Pero me vi bastante forzado a hacerlo, porque no se lo quería pedir a un banco. Preferí pedir la pasta a mis padres y luego se la devolveré.

Clara: El pacto que tenía con mi madre, de que me pagara los estudios, lo he reenganchado ahora, porque sola no me los podía pagar.

Entre nuestros entrevistados es bastante común que la reconversión se dirija hacia el sector de la educación. Quizás esto se podría atribuir al habitus familiar, puesto que muchos de ellos son hijos de profesores. Pongamos de relieve algunos ejemplos. Emilia, de 30 años, había realizado la licenciatura de Biotecnología y un máster en Ciencias Ambientales. Después de estar en situación de desempleo, comenzó a trabajar como monitora de niños «pensando que sería algo temporal», pero finalmente permaneció en tal ocupación. Así pues, optó por empezar el grado de Magisterio y aspira a devenir maestra de primaria. Por su parte, Lluc de 33 años, obtuvo el DEA en Sociología y posteriormente trabajó durante cinco años en un instituto de investigación. $\mathrm{Al}$ perder este empleo, realizó un máster en Formación del Profesorado. En el momento de la entrevista tenía un empleo de camarero y a su vez estudiaba Geografía e Historia para presentarse a las oposiciones y devenir profesor de educación secundaria.

Este tipo de reconversión se piensa como un proceso encaminado hacia la «estabilidad laboral», pero que tendrá sus «frutos» más bien a largo plazo. En esta encrucijada, los entrevistados revelan un sentimiento ambivalente con respecto a sus nuevas perspectivas profesionales. Por un lado, dicen sentirse «tranquilos», porque «saben lo que quieren y hacia dónde van». Por otro lado, expresan cierta decepción, por los años que probablemente les requerirá encontrar una "plaza» y reenclasarse socialmente — tanto en términos de estatus educativo-social como en relación con la clase social de origen.

En otros sectores de actividad, la concretización de la reconversión también parece hacerse esperar. A este respecto, los individuos evocan la dificultad de que se les reconozca su experiencia laboral («camuflada») y ligada al nuevo campo profesional. Martina, de 37 años (quien decidió realizar un máster en Comunicación Científica, tras poseer un postdoctorado en Biotecnología y vivir la experiencia del desempleo), en el siguiente extracto de entrevista, nos cuenta su situación:

Martina: [...] estuve haciendo un máster de Comunicación Científica [...] realmente lo hice para reciclarme, abrirme puertas... [...] y al final aprendí y me gustó la experiencia. Pero fue muy caro y no me sirvió. [...] Y he estado 
haciendo cursillos, y, claro, enviando currículums a todos lados. Intentando siempre fuera del mundo de la investigación. Y por eso es que no he ido ni a una entrevista. Porque siempre dicen: «Ah, no, es que no tienes experiencia laboral en este campo». Entonces es: «Bueno, en realidad la tengo, pero está camuflada dentro de un doctorado y un postdoc».

Por lo general, el mercado laboral se asimila a un terreno hostil, en el que no es suficiente el hecho de estar bien preparado o bien predispuesto, porque hay factores que operan por encima de tales cuestiones. Es por ello que algunos de los entrevistados afirman que su formación para la reconversión ha estado supeditada a los eventuales «nichos de empleo» («Mi elección fue ver qué ofertas hay y qué empleos pueden haber. Por primera vez en mi vida, he decidido racionalmente seguir estudiando», señala Clara) y aspiran a que estos les permita realmente prosperar en términos de ingresos.

En búsqueda de tales nichos profesionales, en ciertos casos, la formación se erige para el autoempleo en un campo de conocimientos y, a su vez, para adquirir habilidades y competencias ligadas a la «figura del emprendedor». Esto se ilustra en el siguiente apartado.

\section{El autoempleo como "estrategia refugio»}

Para hacer frente al desclasamiento, otra lógica estratégica que se despliega en este perfil social es el autoempleo. La estrategia del autoempleo como «estrategia refugio", para salir del desempleo o de los empleos poco cualificados, ya se ha evidenciado en diversos trabajos (Román et al., 2013; Solé et al., 2009; Oso y Villares, 2006).

Según Román et al. (2013: 153), tres grupos se pueden distinguir entre aquellos desempleados que devienen autónomos. En primer lugar, aquellos que responden a un perfil de emprendedor en sentido estricto y que, por tanto, cambian su estatus laboral con el objetivo de iniciar una actividad empresarial que, en el medio y largo plazo, puede implicar una innovación y la contratación de otros trabajadores. En segundo lugar, aquellos que, después de una situación de desempleo (de larga duración), se ven forzados a asumir el estatus de autónomo. Por último, aquellos que estando desempleados reciben una oferta de empleo, pero condicionada a asumir el estatus de autónomo ${ }^{4}$.

Ahora bien, en el transcurso de la crisis económica cabe tener en cuenta que tal lógica estratégica también se ha fomentado por parte del Estado. Siguiendo las recomendaciones de la Comisión Europea, se produce en España una instrumentalización de las políticas de promoción del emprendimiento, la cual se puede observar en los compromisos adquiridos por el gobierno en los sucesivos planes nacionales de reforma (Martínez y Bogino-Larrambebere, 2015). El fomento del autoempleo, fundamentalmente, se ha movilizado a tra-

4. Este último caso se presenta de forma más notoria en el siguiente perfil social de nuestros entrevistados. 
vés de cuatro grandes mecanismos: reducciones o bonificaciones en las cuotas a la Seguridad Social, capitalización de prestaciones por desempleo, subvenciones para el inicio de la actividad por cuenta propia y capacitación. Aunque durante los años de crisis económica los esfuerzos se han concentrado en los dos primeros (Miguélez, 2015).

Retomando el caso de Clara, por ejemplo, después de estar en situación de desempleo, se plantea, junto con otros amigos, crear una asesoría («plataforma de profesionales») para gestionar fondos públicos a las empresas - sobre todo aquellos que provienen de la Unión Europea-. En total son cinco personas en el nuevo emprendimiento, entre las cuales tres de ellas estaban sin empleo y dos tenían un empleo de media jornada. En el momento de la entrevista, Clara nos cuenta que habían podido preparar y vender algunos proyectos, pero que todavía no se habían constituido como empresa y que por el momento sus ganancias no eran realmente cuantiosas («Asumimos que de momento iremos a pérdida y luego ya remontaremos»). El hecho de «tener que reinventarse» en el plano profesional y emplear la modalidad del autoempleo constituye así una «sensación de reto» para nuestra entrevistada:

Clara: Me genera una sensación de reto... de a ver si puedo hacerlo. La cosa de estar estancada profesionalmente me agobiaba un poco. Entonces, ahora es: «Bueno, puedo reinventarme otra vez». Y ahora, además, como tengo que hacerlo, no tengo que buscar excusas para dejar el trabajo.

Uno de los principales recursos con los que cuenta Clara para su emprendimiento es el manejo del inglés (idioma en el que suelen escribir los proyectos) y la experiencia laboral en la realización de proyectos de investigación europeos, que ha adquirido mientras trabajaba anteriormente para una fundación. Paralelamente, esta entrevistada realiza un máster y asiste a los «eventos de emprendedores» para aprender «hábitos y códigos de comportamientos» (formas de vestir, vocabulario que se utiliza, etc.). Su propósito es abrirse al mercado de las empresas extranjeras.

En este caso el autoempleo se percibe como una forma de rehuir de las condiciones de empleo (salarios bajos, jornadas laborales largas, etc.) que ofrece el mercado de trabajo a los asalariados, sobre todo desde el comienzo de la crisis económica. Pero también se concibe como una vía propicia para tener mayor flexibilidad de horarios, lo que supuestamente facilitará la conciliación entre la vida laboral y la familiar (cuidado de los hijos). Efectivamente, el hecho de establecerse por cuenta propia aparece en la representación de las mujeres como un vector para gestionar mejor su tiempo de trabajo productivo y reproductivo, tal y como se pone de manifiesto en otros estudios que abordan la cuestión del autoempleo desde una perspectiva de género (Solé et al., 2009; Oso y Villares, 2006). Por otra parte, si bien la entrevistada no lo dice explícitamente, hay que tener en cuenta que su pareja contaba con cierta estabilidad en el empleo, por lo que es plausible de suponer que esto puede constituir un factor importante a la hora de establecer la estrategia del autoempleo. 
Clara: El panorama laboral es desolador. Y no quiero trabajar en las condiciones que ofrece el mercado. O sea, además que no hay trabajo, los trabajos que hay son con salarios muy bajos. Los horarios también son terribles. Y aparte de la dureza económica actual, a mí me generaría muchísima angustia no poder hacer una vida de madre.

Aun así, la preocupación por la inseguridad en términos de ingresos que conlleva el autoempleo se presenta en el relato de varios entrevistados. Este es el caso de Pau (licenciado en Química de 32 años), quien, tras estar más de un año en situación de desempleo, dice que, «obligado por la situación», optó por establecer un taller de reparación de bicicletas junto con un amigo. Este entrevistado piensa darse de alta como autónomo, aunque se muestra crítico respecto a la política de fomento del emprendimiento y resalta que su mayor temor es que el «tema del emprendedor se convierta en el fondo en la nueva hipoteca», en el sentido de que el Estado lo fomenta con una ayuda mínima y sus peligros recaen en la responsabilidad del individuo.

PAU: Es un proyecto que me interesa, pero obligado por la situación. Si tuviera más posibilidades creo que me plantearía otra cosa [...]. Lo que me da también un poco de miedo es todo este tema del emprendedor, ¿no? Que se traen ahora y tal... que en el fondo es la nueva hipoteca. Es: «te dejamos mucha pasta para que la metas en tu negocio, y luego, si no te va bien, es tu problema». [...] Esto de fomentar el emprendimiento es plantear la ley de la jungla, que cada uno se busque la vida.

Por último, cabe mencionar que para algunos de estos entrevistados la estrategia de la inmigración aparece como alternativa (como "plan B») en caso de que no puedan salir adelante con sus emprendimientos, resaltando que ahora están dispuestos a tomar "decisiones radicales» y que a su vez cuentan con ciertos recursos para ello: "Yo he podido formarme, he podido viajar $y$ vivir en otros países. Entonces, si el día de mañana tengo que emigrar a otro país, creo que tendré menos problemas que otras personas que no han tenido las mismas oportunidades», dice Sara. A la inversa, otros de los entrevistados directamente descartan la posibilidad de emigrar, destacando la pérdida del rol de su capital social a la hora de intentar buscar empleo en otro país: «Si te vas al extranjero pierdes un punto que está bien, que es el del entorno, ¿no? [...] Aparte del trabajo que busco yo, está la gente que sabe que busco trabajo. Si yo me voy a Alemania, no voy a poder tener todo eso... [...] fuera de Barcelona nadie haría nada», expresa Pau.

\subsubsection{Resituarse}

Esta experiencia se inscribe en el perfil social que reúne a los titulados que provienen de una familia de clase social más rica en capital económico que en capital cultural, en la que el padre y/o la madre tienen un nivel de educación medio (educación secundaria de segunda etapa) y son directivos de una pequeña empresa o empleados de banca. Para hacer frente al desclasamiento 
social educativo, la lógica estratégica que se presenta prioritaria en el haz de posibles de este tipo de perfil es la de «resituarse» por medio de la «emigración» o por el hecho de «devenir autónomo" y con el propósito de responder a sus ambiciones profesionales.

\section{Emigrar para evitar el desclasamiento}

La hipótesis de la estrategia migratoria como estrategia para evitar el desclasamiento ha sido demostrada empíricamente en otros trabajos (Jiménez-Zunino, 2012). Las historias de treintañeros con título que deciden emigrar son a menudo recurrentes en los medios de comunicación, especialmente desde el comienzo de la crisis económica. A su vez, en un estudio titulado La nueva emigración española (González-Ferrer, 2013), se indica que el flujo migratorio se invirtió a partir de 2011: son más las personas que abandonan España que las que llegan a ella. Además, se señala que hay que tener en cuenta que los datos oficiales sobre emigración se basan exclusivamente en las bajas padronales, por lo que únicamente se producen si los emigrados se dan de alta en los consulados de España en el exterior. No obstante, esta inscripción raramente se lleva a cabo, puesto que sus beneficios son escasos y sus costes son altos. Por ejemplo: se puede perder el médico de cabecera al que se acude si se regresa de visita, no se puede permanecer inscrito como beneficiario posible de una vivienda de protección oficial y tampoco se puede votar en las elecciones municipales de un pueblo o una ciudad (González-Ferrer, 2013: 4). En este estudio también se destaca que la emigración española básicamente está compuesta por individuos que han terminado sus estudios superiores (emigración cualificada) y que entre los titulados de 30 a 35 años la disposición de marcharse por un tiempo prolongado es mayor que la de marcharse por un tiempo limitado. Si bien se concluye que tal emigración está estrechamente vinculada con la crisis económica, las fuentes disponibles no permiten ahondar en las circunstancias en las que se encuentran los individuos antes de la partida: si estaban en situación de desempleo o tenían un empleo en el que sus expectativas de pretensión laboral y/o salarial se habían visto truncadas.

Nuestros entrevistados, por su parte, aceptan una oferta laboral en el extranjero o planifican su emigración para dedicarse profesionalmente a «lo suyo" y con el propósito de lograr un reenclasamiento en términos de estatus educativo-social. Estos ya han tenido una experiencia de estudios o profesional en el extranjero, cuentan con un nivel de idiomas relativamente elevado (particularmente el inglés) y no tienen cargas familiares.

Ana (32 años, máster y empleada en una consultoría), por ejemplo, tras finalizar la carrera de Ingeniería Técnica en Química, había estado en Inglaterra durante casi nueve meses para afianzar su inglés. En el momento de la entrevista, después de estar seis años en la misma empresa, estaba trabajando a jornada completa por un salario entre 1.000 y 1.200 euros netos mensuales. Ella se siente «estancada» en su empleo, sin perspectivas de disfrutar de ninguna promoción laboral ni de «ejercer aquello que anhela». Es soltera y vive en un piso de alquiler que comparte con otras personas. Por el momento, la mater- 
nidad no forma parte de su proyecto de vida a corto plazo, aunque se siente en una situación ambivalente: le gustaría tener hijos y cree que lo aconsejable es ser madre entre los 30 y los 35 años, pero realmente considera que no lo será durante este periodo. Tanto es así que su principal lógica estratégica para hacer frente al desclasamiento social educativo es conseguir un empleo de ingeniera técnica en el extranjero, especialmente en Asia. Este destino lo ve más viable en comparación con otros países de Europa o de Sudamérica. Para ello va rastreando las ofertas de empleo vía Internet y va enviando su curriculum vitae a diferentes empresas.

Emma (32 años, licenciada en Biología y auxiliar administrativa) se encuentra en una situación similar a la de Ana, en el sentido de que tiene un empleo que no corresponde a sus expectativas y expresa insatisfacción laboral, a la vez que es soltera y vive en un piso que comparte con otras personas. Si bien ella manifiesta estar buscando otro trabajo en España mientras se encuentre activa laboralmente, en caso de perder el empleo que ahora tiene, la primera alternativa (disposición) que se plantea es la emigrar:

Емма: Yo espero poder encontrar un trabajo que me llene a nivel personal. Si consigo realmente ser profe o si encuentro un proyecto, para mí lo importante es que me agrade lo que esté haciendo. Ya que hay que dedicar tantas horas al trabajo, por lo menos que sea más o menos agradable. Pero si no, me voy a otro país. Si me quedo sin trabajo, me iré, porque yo creo que hoy en día ya se ha abierto todo.

Efectivamente, Joan (arquitecto técnico de 33 años) tomó la decisión de emigrar después de estar diez meses en situación de desempleo. En el transcurso de este periodo, trataba de encontrar una ocupación profesional que no se desvinculase de su formación enviando su currículum a varias ofertas de empleo, hasta que le llamaron para trabajar de técnico en el marco de un proyecto de obra industrial en China. Después de dos años y medio en China, Joan toma la decisión de regresar por motivos familiares, específicamente porque su pareja había mantenido su residencia habitual en España. A este respecto, como se estima en otros estudios (Villar y Hernández, 2011), el nivel de formación y laboral de la eventual pareja parece constituir un factor determinante para continuar una trayectoria profesional en el extranjero, dado que si aquella tiene un nivel alto es posible que le sea más difícil prescindir de su empleo y acompañar a la pareja en el extranjero.

Para conseguir el contrato e irse a China, la empresa había requerido a Joan que se hiciera autónomo. A su regreso pensaba que quizás podía formar parte de la plantilla de esta empresa en Barcelona, pero se ha tenido que salvaguardar en la figura laboral que le habían ofrecido, conocida como "falso autónomo»5.

5. El término falso autónomo hace referencia a los individuos que las empresas contratan a condición de que se den de alta en la Seguridad Social como si fuesen autónomos. En efecto, estos pagan su Seguridad Social, aunque en realidad trabajan regularmente para una sola empresa. 
Esta no mantiene una relación laboral con la empresa, sino una vinculación contractual mercantil (Castillo, 2015: 113), de modo que sus derechos como trabajador son menores que si estuviera dado de alta con un contrato laboral ${ }^{6}$.

Ahora bien, a raíz de su vivencia de desclasamiento social, se puede notar en Joan una actitud de activación inmediata y de entrelazamiento de estrategias de reproducción social. En lo que concierne a la primera cuestión, a modo de ejemplo, este entrevistado expresa:

JOAN: Yo ya he sufrido diez meses de paro y no me sirve esto de: «Bueno, un par de meses tranquilo y luego veré». No. Yo estaba en China y estaba pensando en lo que haría al día siguiente de dejar el avión. Y así lo hice. Porque está lo demasiado complicado como para no dormir ni un minuto y estar siempre despierto.

En su relato, igualmente hace énfasis en «insistir» y en «cuidar a sus contactos», aspectos que forman parte de su lógica estratégica y que a su juicio le distinguen de su grupo de pares, particularmente de aquel que proviene del sector de la construcción y se ha visto considerablemente afectado por la crisis económica, teniendo que - en varios casos- desvincularse de su profesión. Esto se puede interpretar como una inclinación hacia la «ideología del esfuerzo» (Moya, 2014) para distinguirse de los demás. En otros términos cabría decir que, en el relato de las dificultades afrontadas y de los obstáculos superados para lograr sus objetivos, destaca el mérito individual y encuentra eco en la figura del self-made-man.

JOAN: Donde veo más la parte oscura del tema es en mi entorno universitario. Porque, claro, estoy en el entorno universitario muy vinculado a la construcción: inmobiliaria y arquitectura. Tengo un compañero que ha estado muy bien y ahora está vendiendo calefactores. Otro que hace dos años que está en paro. Pero también, ya no vale enviar tu currículum a Infojobs. Eso es de hace 20 años. Ahora tienes que hablar con uno, hablar con otro... Si tienes que esperar toda una mañana al director de recursos humanos, ahí te quedas. Y cuidar a tus contactos. Por eso yo siempre digo a mis amigos: «¿Cuidan a sus contactos?», «¿no?». Entonces, los que están en mi sector están jodidos. Yo ahora me considero un afortunado, porque ya un $40 \%$ de mis conocidos no están en el sector. Ahora también, yo acepté cosas que ellos siempre me dicen que no hubieran aceptado. Me fui a China a vivir solo y a pasarlas putas. [...] Pero lo que tiene un precio alto suele tener una buena recompensa.

6. Por ejemplo, en comparación con el asalariado para el mismo trabajo, el falso autónomo muestra las características siguientes: a) debe cotizar su régimen de trabajador autónomo; b) tiene que pagar IVA por las facturas que emite y un IRPF superior, y $c$ ) no tiene garantizado un salario mínimo ni el derecho a la ayuda por desempleo. Además, en el caso de las mujeres, $d$ ) el permiso de maternidad depende de la edad de la trabajadora, de los días cotizados y de la base de cotización — al mismo tiempo que debe seguir pagando su cuota de autónoma-, y el permiso por lactancia no está contemplado. 
En lo que concierne al entrelazamiento de las estrategias, es posible observar que la decisión de emigrar ha permitido a nuestro entrevistado establecer otro tipo de estrategia. En concreto, Joan nos cuenta que había decidido invertir el dinero ganado en China en su formación y que estaba por comenzar un máster sobre gestión empresarial en una reconocida escuela de negocios.

JoAn: Yo lo voy a hacer [el máster], porque me he ido dos años y medio a China. Voy a invertir el dinero que he ganado allí en la mejor escuela de negocios que hay en España. Podía haber hecho otras cosas. Pensaba estudiar otro idioma... Hablo un poco de chino y pensaba estudiar chino. Pero no, información errónea.

Este tipo de estrategia de apelar a la formación suele ser bastante recurrente en el perfil de individuos que tienen un origen familiar rico en capital cultural y, simultáneamente, tienen el propósito de cambiar de campo profesional. En este perfil, en cambio, se implementa en menor medida y, pese a ser la misma estrategia, se establece de modo diferente. Esto es, se recurre a unos recursos económicos que no provienen de la solidaridad familiar, sino del mercado de trabajo o del mercado financiero (préstamo bancario).

En el caso de Joan, esta estrategia además apunta a reconvertir el capital poseído (capital económico) a la vez en capital cultural y en capital social — sin olvidar, seguramente, su adicional capital simbólico, basado en el reconocimiento colectivo- En otras palabras, el hecho de realizar un máster en una prestigiosa escuela de negocios no solo le proporciona un título, nuevos conocimiento y habilidades, sino que también le brinda el acceso a una "red de contactos» proveniente del mundo empresarial y de las clases privilegiadas. Tal y como afirma Marqués (2015: 150): «en España, las escuelas de negocios privadas suponen un escenario ideal para generar capital social. Los costosos másteres que estos centros ofrecen (MBA: Master of Business Administration) sirven para cooptar miembros de la élite empresarial». Por eso, como se deduce del discurso de nuestro entrevistado, el capital social que se puede generar al estudiar en este tipo de escuela constituye un activo crucial en el mercado de trabajo.

\section{Devenir autónomo por necesidad}

Otros de los entrevistados de este perfil son más proclives a la lógica estratégica de devenir autónomo. Cabe aclarar que esta orientación es más por necesidad que por oportunidad. Este es el caso de Danilo (soltero de 36 años), que decide hacerse autónomo "para conseguir poner un pie» en el mundo del cine documental. Pero la irregularidad de los contratos de alta y de baja por servicios hizo que le fuera insostenible mantenerse como autónomo y en el momento de la entrevista estaba jurídicamente en situación de desempleado - aunque seguía trabajando para una institución ${ }^{7}$, primero como autónomo y en el últi-

7. En el momento de la entrevista hacía alrededor de cuatro años que trabajaba para la misma institución. 
mo tiempo de forma informal, en razón del descenso del presupuesto con el que contaba el empleador-. Ciertamente, hay algunos trabajadores que se ven obligados a dar su mano de obra sin contrato y sin poder emitir factura, no por defraudar, sino por precariedad. Esto de los no contratos de hecho es el flanco más débil del mercado de trabajo en España y se trata de unas cifras cada vez más grandes en los años de la crisis económica (Castillo, 2015). Se estima que la economía sumergida supone más del $20 \%$ del PIB de España, por lo que ha desempeñado un gran papel en la expansión del precariado (Standing, 2013).

Pese a las malas condiciones laborales que debe afrontar, nuestro entrevistado siente que el mundo de las artes visuales, en el contexto de su ciudad, es su «campo de batalla». Es el ámbito en el que desea permanecer y desarrollarse profesionalmente. Aunque, en caso de no ser posible, no descarta la posibilidad de emigrar. Eso sí, como se ha visto en los otros casos, el hecho de establecerse en otro país solamente se percibe como una vía para «realizarse» en el trabajo. El tipo de actividad profesional es un elemento central de su identidad.

DANILO: Es curioso, porque tuve una conversación interesante con amigos, dos de ellos músicos, con bastante precariedad, con la necesidad de sacar muchas veces las castañas del fuego, y sí que hablamos: «Tío, sea como sea, es que es aquí donde yo puedo hacer algo. No sé si me voy a morir de hambre o esto va a ser un descalabro absoluto, pero yo, ya, es aquí, eso está claro». Este es mi campo de batalla... [...], básicamente porque yo creo que hay que dedicarse a lo que uno cree. Es la única forma de aportar algo, no hay otra. Y entonces, claro, necesitamos que eso se pueda convertir en un mínimo modo de vivir. Tener una fuente de ingresos, la justa y necesaria, que corresponda al nivel de vida y a las exigencias económicas que tiene un país... [...].

ENTREVISTADORA: ¿Y has pensado en alternativas?

Danilo: Lo intento. Pero llega un momento, como que ya basta de otras alternativas. Hay que tener un plan B, sin duda, ahora mismo. Pero preferiría no tener que hacerlo, porque ya cansa. Hay un punto de derrota. Que si tienes que hacerlo, pues ya está y tiras... No pasa nada. No se te caen los anillos. Pero sabes que tienes que hacer eso porque no hay forma de que puedas hacer otra cosa. De momento, ahí estamos..., andando por el límite del barranco.

Esta estrategia de devenir autónomo por necesidad también se baraja como haz de posibles en el caso de Lucía. En el momento de realizar la entrevista esta tiene un empleo con un horario laboral por las tardes (que no podía cambiar) y hacía unos pocos meses que había sido madre primeriza. A raíz de la llegada de su hija se plantea la posibilidad de convertirse en autónoma, con el propósito de poder pasar las tardes con su pequeña. Al igual que en el perfil anterior, algunas de las mujeres de esta muestra perciben que, si se orientan hacia el trabajo por cuenta propia, podrán conciliar más fácilmente la vida laboral y la familiar. Este aspecto aparece en el discurso de las mujeres, específicamente en aquellas que son madres. Por el contrario, se encuentra ausente en el discurso de los hombres. 


\subsubsection{Resistir}

Esta experiencia se inscribe fundamentalmente en el perfil social menos afectado por el desclasamiento, el cual aglutina a los titulados que provienen de una familia de clase media-baja y de clase trabajadora, en el que la madre y el padre destacan con un nivel de educación bajo (educación secundaria de primera etapa o inferior). Para hacer frente al desclasamiento social educativo, la lógica estratégica que se presenta prioritaria en el haz de posibles de este tipo de perfil social es la de tratar de mantenerse en sus empleos y/o intentar acceder al empleo público. Esta apunta más hacia la idea de «no caer» aún más en la escala social y conservar la seguridad económica en el empleo, que la de reenclasamiento social en lo que concierne a su logro educativo o la de resituarse en relación con sus ambiciones profesionales. Varios de estos individuos, por tanto, se inclinan por reajustar sus ambiciones profesionales iniciales hacia la baja. Esto hace referencia a lo que Goffman (1987) denomina «enfriamiento de las expectativas» (cooling out).

\section{Mantenerse en sus empleos para evitar la pauperización}

El contexto de crisis económica ha «limitado el horizonte profesional» de estos entrevistados. Al menos a corto plazo, estos presentan una visión desencantada de sus posibilidades de ascenso en el mercado de trabajo. Si bien, por un lado, su trayectoria educativa les incita a poner en marcha estrategias para salir del desclasamiento y esforzarse por adquirir un empleo que esté más a la altura de sus títulos superiores y de sus propios intereses socioprofesionales; por otro lado, el aumento del desempleo en el contexto de crisis económica hace que sus aspiraciones de ascenso profesional se frenen, traten de conformarse con la idea de tener un empleo y tiendan a aceptar sus empleos como una oportunidad, incluso como una "ventaja». La expresión "al menos tengo un trabajo», cuando "hay tanta gente que no lo tiene», suele ser bastante usual en sus discursos. Es por ello que, sin eludir la dificultad de reorientar su trayectoria laboral — particularmente por la considerable carga horaria de sus jornadas laborales y posiblemente por estar más desprovistos de capital social (Beaud, 2003) que los otros perfiles sociales para acceder a un empleo elevado-, estos individuos declaran tener una cierta voluntad de mantenerse en sus empleos. Bernat (30 años, máster en Historia y auxiliar de librería) hace alusión a tales aspectos en su testimonio:

Bernat: [...] la crisis me ha afectado en cuanto a mi horizonte laboral. Ahora tengo un horizonte laboral mucho más limitado. [...] Ahora mismo, la idea es mantenerme en mi trabajo. Además, mi trabajo actual me limita mucho... Quieras o no, soy un esclavo a tiempo parcial, eh. Remunerado, pero estás ahí cuarenta horas a la semana, y cuesta realizar cosas fuera del trabajo, sobre todo cuando es en un horario rarísimo. Entonces, ahora mismo, mi perspectiva sería estar unos años más en el trabajo... y depende cómo estén las cosas... quieras o no, es un trabajo y, bueno, tengo una cierta voluntad de mantenerlo.

En estos casos, la cuestión del agravamiento del desempleo es el punto de referencia más inmediato para juzgar su situación. Esta, en cierto modo, ejerce 
de amortiguador. Estar «ocupados», independientemente de la naturaleza de sus empleos, es vivido positivamente o al menos como un mal menor. A la inversa, caer en el desempleo, constituye su principal temor.

Agustí: Hoy en día pienso más si me voy a mantener. Si se me acaba todo el chollo o no. Debido a los recortes y a lo que me sucedió: ahora no cobras, ahora sí. Y te puedes quedar en la calle. Obviamente, una preocupación es: «ंme voy a mantener?», «¿voy a seguir aquí al menos durante seis meses?». No lo sé, eh. Pero tal y como están las cosas, voy a hacer todo lo posible por tratar de mantenerme en este empleo.

Esto no significa, no obstante, que no salvaguarden la esperanza de salir de la situación de desclasamiento y puedan conseguir un «mejor» empleo en el futuro. Pese a que atraviesan un periodo difícil y puntualizan que "siempre han partido de lugares mínimos» en términos laborales, tratan de mantener la confianza de que algún día sus méritos les serán reconocidos.

\section{Acceder a un empleo público para asegurarse estabilidad}

Para hacer frente al desclasamiento, otra lógica estratégica de segundo orden que se despliega en este perfil social es la de tratar de acceder a un empleo público. El empleo público constituye una salida favorable para asegurarse una «estabilidad económica y de trabajo». Magda, de 35 años y titulada en Sociología, hace casi diez años que trabaja de interina como auxiliar de control en un instituto. Y, paralelamente, se prepara las oposiciones para devenir profesora de educación secundaria. Si bien ya se ha presentado una vez a tales oposiciones y no ha logrado acceder a una plaza, su intención es seguir intentando cambiar de empleo por medio de esta vía. Sin eludir que el periodo de oposiciones le «desgasta mucho psicológicamente» — dado que siente que se «esfuerza y no llega»—, esta entrevistada evoca que su decisión de hacer las oposiciones sobre todo se asocia a la idea de rehuir de la incertidumbre de la inestabilidad laboral. Y, de modo subsiguiente, aquella de realizar una actividad profesional más vinculada a su formación.

Magda: A mí me genera mucha incertidumbre la inestabilidad laboral. El hecho de que en cualquier momento te puedas ver en la calle, con una edad en la que ya es muy difícil que te contraten. Yo he estado muchos años trabajando, pero he tenido trabajos que en ninguna empresa me los tendrán en cuenta. Entonces, por eso decidí hacer las oposiciones, porque pienso que me dará estabilidad.

Tal orientación hacia el empleo público igualmente la encontramos entre algunos de los entrevistados de este perfil que se encuentran en situación en desempleo. Antes de inclinarse por restringir considerablemente sus ambiciones profesionales («relajarme, trabajar de administrativa y ya está»), el empleo público se concibe como una senda eventualmente viable por dos razones fundamentales: la falta de capital social necesario para activarse en el sector 
privado y la aspiración de dedicarse a una actividad laboral más cercana a sus intereses personales. A su vez, como se nota en la cita de arriba y en la siguiente, este aparece como una vía proclive a salvaguardar el «hándicap» de la edad para acceder a un empleo elevado, básicamente después de haber pasado por trabajos pocos cualificados y de haber vivido largos periodos de desempleo.

EnTREVISTADORA: ¿Y qué expectativas de futuro tienes en relación con el trabajo?

Elisa: ¡Puf? No sé. La verdad es que lo veo un poco negro... Veo ya que con los años..., bueno, yo no me veo mayor, pero veo que para el mercado de trabajo soy mayor y eso es un hándicap. Entonces estoy intentando posibilidades de empleo público que me apetezcan..., pero tampoco salen cosas. Entonces no sé si la solución está por ahí o qué..., o está por relajarme, trabajar de administrativa y ya está.

\section{Conclusiones}

En este artículo se ha identificado una tipología de los perfiles sociales de los titulados afectados por el desclasamiento y se ha desentrañado sus lógicas estratégicas ante tal fenómeno, en el seno de la cohorte de treintañeros y en el contexto de crisis económica.

En la determinación de estos perfiles resulta particularmente relevante el origen social de los titulados desclasados, mediado en primer lugar por el nivel educativo (tanto del padre como de la madre) y en segundo lugar por la ocupación (tanto del padre como de la madre). El papel del nivel de educación superior de los individuos, si bien es significativamente discriminatorio, define en menor medida a los diferentes tipos de perfiles. El sexo y el grupo de edad son elementos aún menos clasificatorios.

Si bien los titulados treintañeros de clases medias y medias-altas no quedan exentos del desclasamiento social educativo, este afecta considerablemente más en términos relativos a un tipo de perfil social en concreto: aquel que está formado sobre todo por individuos que provienen de una familia de clase media-baja y de clase trabajadora, en el que la madre y el padre principalmente poseen un nivel de educación bajo.

Específicamente se han distinguido tres tipos de perfiles sociales. Uno de ellos (un 10\% de los casos) está compuesto fundamentalmente por individuos que provienen de una familia de clase media-alta, rica ante todo en capital cultural, cuyos padres destacan por un nivel de educación alto y son profesionales. Un segundo perfil (un 15\% de los casos) está formado principalmente por hijos e hijas de madres y de padres con un nivel de educación medio y son directivos o empleados. Un tercer perfil (un $75 \%$ de los casos) está integrado esencialmente por individuos que provienen de una familia de clase media-baja y de clase trabajadora, en el que el padre y la madre destacan con un nivel de educación bajo y son obreros. Este análisis sugiere abordar la cuestión de los titulados desclasados, tomando prioritariamente en consideración el nivel de 
educación de la familia de origen de los individuos. Este criterio, identificado empíricamente y sustentado por la fundamentación teórica, es el que ha prevalecido en la selección de los titulados desclasados que se han entrevistado en el trabajo de campo cualitativo.

Así, a partir de un análisis de comparación de los diferentes relatos, se ha procurado resaltar los rasgos principales que hacen más inteligible el sentido de las experiencias para cada uno de los perfiles sociales y se han distinguido los siguientes modos de hacer frente al desclasamiento: reconvertirse, resituarse y resistir.

Reconvertirse es la experiencia que se inscribe fundamentalmente en la lógica del reenclasamiento social por medio de la reconversión profesional de los actores. Este tipo de experiencia concentra a los titulados que provienen de una familia de clase media-alta con elevado capital cultural, en la que el padre y/o la madre poseen un nivel de educación superior y son profesionales. Para hacer frente al desclasamiento social educativo los entrevistados de este tipo de perfil social se «reconvierten" a nivel profesional y se desplazan de campo laboral, con la idea de reenclasarse socialmente. Recurren así a la estrategia de «formarse» (realizan estudios de grado o de postgrado, con la ayuda económica familiar y con el propósito de «hacerse empleables») y/o de «emprender su propio negocio" (junto con amigos o conocidos, que a menudo poseen antecedentes e intereses similares). Esto último se percibe, para la mayoría de los entrevistados, como una forma de eludir el desempleo y de rehuir las condiciones precarias de trabajo que ofrece el mercado laboral a los asalariados, sobre todo desde el comienzo de la crisis económica. En el caso particular de las mujeres, además, se percibe como una vía plausible que supuestamente les facilitará la conciliación entre la vida laboral y la familiar.

Resituarse es la experiencia que reside primordialmente en la lógica de responder a las ambiciones profesionales por medio de un cambio del contexto o de la situación laboral en la que se encuentran los individuos. Este tipo de experiencia reúne a los titulados que provienen de una familia de clase social más rica en capital económico que en capital cultural, en la que el padre y/o la madre tienen un nivel de educación medio (educación secundaria de segunda etapa) y son directivos de una pequeña empresa o empleados de banca. Para hacer frente al desclasamiento social educativo, los entrevistados de este tipo de perfil social se desplazan geográficamente o de régimen de empleo para responder a sus ambiciones profesionales: dedicarse a aquello en lo que "creen", que les «ilusiona» y que les permite «desarrollarse profesionalmente». En este sentido, se plantean la "estrategia migratoria", sobre todo quienes previamente habían tenido una experiencia de estudios o profesional en el extranjero, saben idiomas y no tienen cargas familiares, o bien se orientan por «devenir autónomos", particularmente quienes han estado antes como asalariados y se convierten en trabajadores por cuenta propia, aunque a menudo siguen trabajando para un solo empleador ${ }^{8}$. Esto lo hacen principalmente "por necesidad",

8. Figura laboral que se conoce como falso autónomo o asalariado encubierto. 
para poder continuar laboralmente activos y con la idea de mantenerse en sus respectivos campos profesionales.

Resistir es la experiencia que se inscribe esencialmente en la lógica de «aguantar para no caer». Este tipo de experiencia aglutina a los titulados que provienen de una familia de clase media-baja y de clase trabajadora, cuyos padres destacan por un nivel de educación bajo (educación secundaria de primera etapa o inferior). Para hacer frente al desclasamiento social, los entrevistados de este tipo de perfil tratan de "mantenerse en sus empleos», por más que no se encuentren realmente a gusto en ellos, y/o intentan «acceder a un empleo público", para evitar la pauperización y asegurarse una cierta estabilidad económica. Teniendo como referente más inmediato la cuestión del aumento del desempleo a lo largo de la crisis económica, estos individuos tienden a reajustar sus ambiciones profesionales iniciales a la baja. Es así que básicamente procuran «no caer» aún más en la escala social, en detrimento de tener la idea de reenclasarse socialmente en lo que concierne a su logro educativo o de resituarse en relación con sus ambiciones profesionales.

Este artículo ha intentado contribuir al estudio sobre la cuestión del desclasamiento social, prestando especial atención al caso de los titulados superiores. A su vez, proporciona un nuevo enfoque para abordar la problemática del desclasamiento y desde la combinación de una doble aproximación: cuantitativa y cualitativa. Este método mixto tiene la intención de tomar en consideración tanto el «sentido objetivo» como el «sentido vivido» (Bourdieu, 1988) de los titulados ante el desclasamiento social. Por último, ofrece una evaluación empírica sobre una cohorte de edad que se encuentra en una fase del ciclo de vida crucial en relación con el enclasamiento social y la formación familiar. Todo esto, además, en un escenario de crisis económica que no se presenta en los estudios previos.

Este trabajo, finalmente, abre la posibilidad de desarrollar futuras líneas de investigación sobre la cuestión del desclasamiento social educativo. Por ejemplo, sería interesante ahondar en la dinámica de las trayectorias de los individuos en situación de desclasamiento social. El análisis estadístico de este artículo ha mostrado una fotografía sobre un momento determinado del tiempo, particularmente en lo que respecta al año 2011. Para avanzar con el análisis, no obstante, sería idóneo realizar estudios longitudinales con el fin de poner a prueba tres tipos de hipótesis que son recurrentes entre los expertos. Desde una perspectiva generacional, la primera hipótesis alude a un «efecto de cohorte» o "efecto cicatriz» (Chauvel, 2016; Marqués, 2015), y consiste en verificar si existe una cronificación o una recuperación del desclasamiento social educativo para la generación abordada. Desde una perspectiva de estratificación social, la segunda hipótesis se refiere a un efecto de "contramovilidad» (Bertaux, 1974) y se podría examinar con relación a dos vertientes: como el movimiento que lleva a los titulados superiores de la cohorte de treintañeros hacia una consistencia de estatus educativo y social (superación del desclasamiento social educativo) o como el movimiento que lleva a los individuos hacia la clase social de origen, después de haber estado un cierto tiempo en otras categorías (reproducción social intergeneracional). Desde una perspectiva de género, la tercera hipótesis 
atañe a un «efecto suelo pegajoso» (sticky floor) (Torns y Recio, 2012) y consiste en verificar las posibilidades para las mujeres de salir del desclasamiento social educativo en comparación con los hombres, y si las trayectorias laborales femeninas están más bloqueadas o estancadas que las masculinas.

\section{Referencias bibliográficas}

ALm, Susanne (2011). «Downward mobility across generations: The role of parental mobility and education». Sociological Research Online, 16, 1-14. $<$ https://doi.org/10.5153/sro.2416>

Baudelot, Christian y Establet, Roger (2000). Avoir 30 ans en 1968 et en 1998. París: Seuil.

BEAUd, Stéphane (2003). 80 \% au bac... et après ?: Les enfants de la démocratisation scolaire. Paris: La Découverte.

Beaud, Stéphane y Weber, Florence (2008). Guide de l'enquête de terrain. París: La Découverte.

Bertaux, Daniel (2005). Los relatos de vida: Perspectiva etnosociológica. Barcelona: Bellatera.

- (1974). «Mobilité sociale biographique. Une critique de l'approche transversale». Revue française de sociologie, 15(3), 329-362. $<$ https://doi.org/10.2307/3320160>

Bogino-Larrambebere, Victoria (2016). Los titulados ante el desclasamiento: Un análisis de la cohorte de treintañeros en España. Universidad Autónoma de Barcelona. Tesis doctoral.

Bourdieu, Pierre (1988). La Distinción: Criterios y bases sociales del gusto. Madrid: Taurus.

Callejo, Javier (1998). «Los límites de la formalización de las prácticas cualitativas de investigación social: la saturación». Sociológica: Revista de Pensamiento Social, 3, 93-120.

Castillo, Juan-José (2015). La invasión del trabajo en la vida. Madrid: Catarata.

Chauvel, Louis (1998). Les destins des générations: Structure sociale et cohortes en France au XX siècle. París: PUF.

- (2006). Les classes moyennes à la dérive. París: Seuil.

- (2016). La spirale du déclassement. París: Seuil.

Domínguez, Màrius y López-RoldÁn, Pedro (1996). «La construcció de tipologies: Procés i tècniques d'anàlisi de dades». Papers, 48, 31-39. $<$ https://doi.org/10.5565/rev/papers.1815>

Duru-Bellat, Marie (2006). L'inflation scolaire: Les désillusions de la méritocratie. París: Seuil.

Elias, Marina y DAZA, Lidia (2014). «Sistema de becas y equidad participativa en la universidad». Revista de la Asociación de Sociología de la Educación, 7(1), 233-251.

Giret, Jean-François; Nauze-Fichet, Emmanuelle y Tomasini, Magda (2006). «Le déclassement des jeunes sur le marché du travail». Données Sociales, 307-314.

Goffman, Erving (1987). La presentación de la persona en la vida cotidiana. Buenos Aires: Amorrortu.

GOLDTHORPE, Jonh y JaCKsON, Michelle (2007). «Intergenerational class mobility in contemporary Britain: Political concerns and empirical findings». The British Journal of Sociology 58, 525-546. <https://doi.org/10.1111/j.1468-4446.2007.00165.x> 
GonZÁlez-FErrer, Amparo (2013). La nueva emigración española. Madrid: Fundación Alternativas.

Gutiérrez, Alicia (2004). Pobre, como siempre: Estrategias de reproducción social en la pobreza. Córdoba: Ferreyra Editor.

- (2005). Las prácticas sociales: Una introducción a Pierre Bourdieu. Córdoba: Ferreyra Editor.

JiméneZ-Zunino, Cecilia (2012). Desclasamiento y reconversiones en las trayectorias de los migrantes argentinos de clases medias. Universidad Complutense de Madrid. Tesis doctoral.

Li, Yaojun y Devine, Fiona (2011). «Is social mobility really declining?: Intergenerational class mobility in Britain in the 1990s and the 2000s». Sociological Research Online, 16, 1-15. <https://doi.org/10.5153/sro.2424>

López-Roldán, Pedro (1996). «La construcción de tipologías: Metodologías de análisis». Papers 48, 9-29. $<$ https://doi.org/10.5565/rev/papers.1811>

Marqués, Ildefonso (2015). La movilidad social en España. Madrid: Catarata.

Martínez, Laureano y Bogino-Larrambebere, Victoria (2015). «La instrumentación en España de las políticas europeas de emprendimiento: ¿Creación de empleo o profundización de la crisis del empleo asalariado?». Revista Eletrônica de Ciência Politica, 6 (1), 187-208. <https://doi.org/10.5380/recp.v6i1.37493>

Maurin, Éric (2009). La peur du déclassement: Une sociologie des récessions. París: Seuil-La République des Idées.

Miguélez, Fausto (coord.) (2015). Diagnóstico socio-económico sobre las políticas de empleo en España, 2012-2014. Bellaterra: Universitat Autònoma de Barcelona. Centre d'Estudis Sociològics sobre la Vida Quotidiana i el Treball.

Moya, José (2014). La ideología del esfuerzo. Madrid: Catarata.

Newman, Katherine (1988). Falling from Grace: The Experience of Downward Mobility in The American Middle Class. Nueva York: Basic Books.

Oso, Laura y Villares, María (2006). «El autoempleo como una estrategia de incorporación laboral para los inmigrantes en Galicia». En: Oso, Laura y Montero, Pablo (coord.). Formación, profesionalización y acción en mediación intercultural. Santiago de Compostela: Universidad da Coruña.

Peugny, Camille (2009). Le déclassement. París: Grasset.

Román, Concepción; Congregado, Emilio y Millán, José (2013). «Start-up incentives: Entrepreneurship policy or active labour market programme?». Journal of Business Venturing (28), 151-175. <https://doi.org/10.1016/j.jbusvent.2012.01.004>

Serrano, Amparo y Crespo, Eduardo (2002). «El discurso de la Unión Europea sobre la sociedad del conocimiento». Revista Española de Investigaciones Sociológicas, (97), 189-207. <https://doi.org/10.2307/40184369>

Solé, Carlota; Parella, Sonia; Ortega, Enrique; Pávez, Iskra y Sabadi, Marc (2009). Las trayectorias sociales de las mujeres inmigrantes no comunitarias en España. Madrid: Instituto de la Mujer.

StAnding, Guy (2013). El precariado: Una nueva clase social. Barcelona: Pasado y Presente.

Thijssen, Lex y Wolbers, Maarten (2016). «Determinants of Intergenerational Downward Mobility in the Netherlands». Social Indicators Research, 128(3), 995-1010. <https://doi.org/10.1007/s11205-015-1066-7> 
Torns, Teresa y Recio, Carolina (20I2). «Las desigualdades de género en el mercado de trabajo: Entre la continuidad y la transformación». Revista de Economía Crítica, $14,178-202$.

Verd, Joan Miquel y López-Roldán, Pedro (2008). «La eficiencia teórica y metodológica de los diseños multimétodo». Empíria, 16, 13-42. $<$ https://doi.org/10.5944/empiria.16.2008.1388>

Villar, Alicia y Hernández, Francesc (2011). De la beca al contracte: Anàlisi sobre les trajectòries de les becàries i dels becaris d'investigació a places de PDI contractat. Valencia: Universidad de Valencia.

Wilson, George (2009). «Downward Mobility of Women from White-Collar Employment: Determinants and Timing by Race». Sociological Forum, 24(2), 382-401. <https://doi.org/10.1111/j.1573-7861.2009.01104.x>

\section{Anexos}

Tabla 3. Distribución de las entrevistas por origen familiar de clase y sexo

\begin{tabular}{|c|c|c|c|c|}
\hline \multirow[b]{2}{*}{ Sexo } & \multicolumn{4}{|c|}{ Orígen familiar de clase } \\
\hline & $\begin{array}{c}\text { Padres con título superior } \\
\text { y profesionales }\end{array}$ & $\begin{array}{l}\text { Padres con nivel educativo } \\
\text { medio y directivos de una pequeña } \\
\text { empresa o empleados de banca }\end{array}$ & $\begin{array}{l}\text { Padres con nivel educativo } \\
\text { bajo y obreros }\end{array}$ & Total \\
\hline \multirow[t]{6}{*}{ Mujeres } & Martina, 37 años, Bioquímica & Emma, 32 años, Biología & Julia, 39 años, Periodismo & 14 \\
\hline & Clara, 35 años, Sociología & Ana, 32 años, Ingeniería Técnica en Química & Alba, 38 años, FP/Trabajo Social & \\
\hline & Laia, 34 años, Filosofía & Lucía, 30 años, Pedagogía & Magda, 35 años, Sociología & \\
\hline & Sara, 31 años, Historia & & Elisa, 35 años, Empresariales & \\
\hline & Emilia, 30 años, Biotecnología & & Rocío, 33 años, Psicología & \\
\hline & & & Inés, 30 años, Filología Inglesa & \\
\hline \multirow[t]{5}{*}{ Hombres } & Joel, 35 años, Periodismo & Danilo, 36 años, Sociología & Agustí, 36 años, FP/Pedagogía & 12 \\
\hline & Lluc,33 años, Humanidades & Toni, 35 años, Psicología & Daniel, 35 años, FP/Empresariales & \\
\hline & Pau, 32 años, Química & Joan, 33 años, Arquitectura Técnica & Albert, 32 años, Periodismo & \\
\hline & Marc, 32 años, Ciencias Ambientales & & Bernat, 30 años, Historia & \\
\hline & Vicent, 30 años, Sociología & & & \\
\hline Total & 10 & 6 & 10 & 26 \\
\hline
\end{tabular}

Fuente: elaboración propia. 
Tabla 4. Características de las personas entrevistadas

\begin{tabular}{|c|c|c|c|c|c|c|c|}
\hline Nombre & Edad & Educación & $\begin{array}{l}\text { Situación } \\
\text { ocupacional }\end{array}$ & $\begin{array}{l}\text { Educación de } \\
\text { la madre }\end{array}$ & $\begin{array}{l}\text { Educación } \\
\text { del padre }\end{array}$ & $\begin{array}{l}\text { Ocupación de } \\
\text { la madre }\end{array}$ & $\begin{array}{l}\text { Ocupación } \\
\text { del padre }\end{array}$ \\
\hline 1. Martina & 37 años & Doctorado & $\begin{array}{l}\text { En desempleo } \\
\text { (larga duración) }\end{array}$ & Doctorado & Doctorado & Profesora de universidad & Jefe de laboratorio \\
\hline 2. Lluc & 33 años & Máster & Camarero & Doctorado & Doctorado & Profesora de universidad & Urbanista \\
\hline 3. Emilia & 30 años & Máster & Monitora de niños & Licenciatura & Doctorado & Profesora de instituto & Profesor de universidad \\
\hline 4. Vicent & 30 años & Licenciatura & Auxiliar de control & Licenciatura & Doctorado & Alta funcionaria & Profesor de universidad \\
\hline 5. Clara & 35 años & Máster & En desempleo & $\mathrm{FP}$ & Licenciatura & Ama de casa & Economista \\
\hline 6. Marc & 32 años & Máster & En desempleo & Licenciatura & Doctorado & Logopeda & Profesor de universidad \\
\hline 7. Laia & 34 años & Máster & $\begin{array}{l}\text { Auxiliar de servicios } \\
\text { sociales }\end{array}$ & Bachillerato & Licenciatura & Agente de seguros & Perito agrícola \\
\hline 8. Pau & 32 años & Licenciatura & $\begin{array}{l}\text { En desempleo } \\
\text { (larga duración) }\end{array}$ & Licenciatura & Licenciatura & Maestra de primaria & Antropólogo/ Bombero \\
\hline 9. Sara & 31 años & Máster & Administrativa & Licenciatura & Licenciatura & Enfermera & Médico \\
\hline 10. Joel & 35 años & Máster & En desempleo & Licenciatura & Doctorado & Profesora de instituto & Profesor de universidad \\
\hline 11. Emma & 32 años & Licenciatura & Auxiliar administrativa & Bachillerato & Bachillerato & Ama de casa & Empleado de banca \\
\hline 12. Joan & 33 años & $\begin{array}{l}\text { Arquitecto } \\
\text { técnico }\end{array}$ & $\begin{array}{l}\text { Ayudante de obra } \\
\text { (falso autónomo) }\end{array}$ & Graduado escolar & Bachillerato & Propietaria de una tienda & $\begin{array}{l}\text { Propietario } \\
\text { de un negocio }\end{array}$ \\
\hline 13. Ana & 32 años & Máster & $\begin{array}{l}\text { Empleada de } \\
\text { una consultoría }\end{array}$ & Graduado escolar & Bachillerato & Ama de casa & Empleado de banca \\
\hline 14. Danilo & 36 años & Máster & En desempleo & Bachillerato & Bachillerato & Contable administrativa & $\begin{array}{l}\text { Técnico en una } \\
\text { empresa }\end{array}$ \\
\hline 15. Lucía & 30 años & Máster & $\begin{array}{l}\text { Auxiliar de servicios } \\
\text { sociales }\end{array}$ & ESO & FP & $\begin{array}{l}\text { Empleada en } \\
\text { una peluquería }\end{array}$ & $\begin{array}{l}\text { Propietario de un taller } \\
\text { mecánico }\end{array}$ \\
\hline 16. Toni & 35 años & Máster & $\begin{array}{l}\text { En desempleo (larga } \\
\text { duración) }\end{array}$ & Bachillerato & FP & Ama de casa & Mecánico naval \\
\hline 17. Magda & a 35 años & Máster & Auxiliar de control & Primaria & Primaria & Ama de casa & Auxiliar de control \\
\hline 18. Daniel & 35 años & $\begin{array}{l}\mathrm{FP} / \\
\text { Diplomatura }\end{array}$ & Auxiliar administrativo & Primaria & Primaria & $\begin{array}{l}\text { Empleada de servicios } \\
\text { de limpieza }\end{array}$ & Camionero \\
\hline 19. Julia & 39 años & Máster & Auxiliar administrativa & Primaria & Primaria & $\begin{array}{l}\text { Empleada de } \\
\text { una panadería }\end{array}$ & Operario de fábrica \\
\hline 20. Bernat & t 30 años & Máster & Auxiliar de librería & Primaria & Primaria & Ama de casa & Conserje de portería \\
\hline 21. Alba & 38 años & $\begin{array}{l}\text { FP/Diploma- } \\
\text { tura }\end{array}$ & $\begin{array}{l}\text { En desempleo } \\
\text { (larga duración) }\end{array}$ & Primaria & Primaria & Ama de casa & Operario de fábrica \\
\hline 22. Agustí & 36 años & FP/Máster & $\begin{array}{l}\text { Auxiliar de servicios } \\
\text { sociales }\end{array}$ & Primaria & $\begin{array}{l}\text { Padre } \\
\text { ausente }\end{array}$ & Operaria de fábrica & Padre ausente \\
\hline 23. Inés & 30 años & Máster & En desempleo & Primaria & Primaria & Empleada como cocinera & Operario de fábrica \\
\hline 24. Albert & 32 años & Máster & Auxiliar administrativo & Primaria & Primaria & Ama de casa & Agricultor \\
\hline 25. Elisa & 35 años & Diplomatura & En desempleo & Primaria & Primaria & Ama de casa & Auxiliar administrativo \\
\hline 26. Rocío & 33 años & Máster & Teleoperadora & Primaria & Primaria & Ama de casa & Operario de fábrica \\
\hline
\end{tabular}

Fuente: elaboración propia. 